\title{
Developmental and Tissue-Specific Modulation of Rat Galactose-1-Phosphate Uridyltransferase Steady State Messenger RNA and Specific Activity Levels
}

\author{
R. A. HEIDENREICH. J. MAlleE, S. ROGERS, AND S. SEGal
}

The Division of Biochemical De'velopment and Molecular Diseases, Department of Pediatrics. The Lniversity of Pennsylyania. The Children's Hospital of Philadelphia. Philadelphia, Pennsylvania 19104

\begin{abstract}
To assess the role of genetic regulation as a modulating factor in the variability of rat tissue galactose1-phosphate uridyltransferase (GALT) sp act, we have determined steady state GALT mRNA and sp act in rat liver during postnatal development. Steady state GALT mRNA levels increase from birth to $\mathrm{d} 5$ and subsequently decrease toward adult levels. GALT sp act mirrors the mRNA pattern. A survey of steady state mRNA and GALT sp act of several adult rat tissues revealed marked tissue differences with a good correlation of the two parameters. Liver had the highest GALT mRNA and sp act; kidney, ovary, and heart had similar but lower mRNA and sp act; skeletaî muscle and testes had the least GALT mRNA and enzyme sp act. These findings suggest that genetic regulation is important in the variable expression of GALT tissue sp act. (Pediatr Res 34: 416-419, 1993)
\end{abstract}

\section{Abbreviations}

GALT, galactose-1-phosphate uridyltransferase rRNA, ribosomal RNA UDP, uridine diphosphate

The metabolism of galactose, a major carbohydrate constituent of almost all animal milk, is controlled by the three enzymes of the Leloir pathway, galactokinase, GALT, and UDP galactose4-epimerase (1). That GALT is a key enzyme in the pathway is highlighted by human galactosemia due to deficient GALT activity. Interest in this recessively inherited disorder has fostered efforts to delineate the mechanism responsible for regulation of GALT activity. We have previously described increases in liver GALT sp act in rats fed a high-galactose diet (2), in pregnant female rat liver, possibly related to progesterone $(3,4)$, and in the postnatal development of rat liver (5). We have also described variation of GALT sp act in different rat tissues (5) and modulation by uridine nucleotides (6). Whether modulation of GALT sp act in these instances is caused by regulation of GALT protein degradation or stability of the enzyme, or is related to control of GALT gene transcription, mRNA translation, or mRNA stability remains to be determined. In recent studies, we've demonstrated that regional differences in rat brain GALT correlate with steady

Received January 6, 1993: accepted May 21, 1993.

Correspondence: R. A. Heidenreich. M.D.. Department of Pediatrics, Section of Genetics, Univ. of Arizona, 1501 North Campbell Ave., Tucson. AZ 85724.

Supported in part by a grant from the National Institutes of Health Clinical Investigator Award HD00855-02 (R.H.). The American Philosophical Society Daland Fellowship. The Thomas B. and Jeanette E. Laws McCabe Fund, Biomedical Research Support grant administered by the Joseph Stokes Research Institute at The Children's Hospital of Philadelphia. and a National Institutes of Health Grant DK42785 (S.S.). state levels of GALT sp act (7). In this report, we have assessed GALT sp act and steady state mRNA during postnatal rat liver development and in various tissues of the adult rat. Our findings that there is a correlation between the two parameters in these investigations indicates that genetic regulation plays an important role in modulating GALT activity. Our findings form the basis of this report.

\section{MATERIALS AND METHODS}

Animals. Timed pregnant Sprague-Dawley rats from Charles River Breeding Farms (Wilmington. MA) were housed three per cage with free access to food and water in a room with a 10:14 $\mathrm{h}$ light:dark cycle. All experiments were performed using the Children's Hospital Animal Investigation Committee guidelines for the care and use of laboratory animals. The animal care program is accredited by the American Association for Accreditation of Laboratory Animal Care. Tissue from exsanguinated animals was dissected. frozen in precooled Wollenberger tongs, and stored at $-70^{\circ} \mathrm{C}$ until removed for RNA and enzyme analysis.

$R N A$ isolation and Northern blotting. Total RNA was isolated by the method of Chomczynski and Sacchi (8). One hundred mg of tissue were homogenized using a Dounce homogenizer in 1 $\mathrm{mL}$ of $4 \mathrm{M}$ guanidinium thiocyanate, $25 \mathrm{mM}$ sodium citrate, $\mathrm{pH} 7,0.5 \%$ SDS, and $0.1 \mathrm{M} 2$-mercaptoethanol. The tissue was transferred to a polypropylene tube and sequentially extracted with acidified phenol and chloroform-isoamyl alcohol $(49: 1)$. The RNA was precipitated with isopropanol and resuspended in $1 \mathrm{~mL}$ of diethylpyrocarbonate-treated water. The RNA concentration was determined by absorption at $260 \mathrm{~nm}$ UV.

Separate Northern blots of RNA obtained from newborn rat liver and adult rat tissues were generated by electrophoresis of $10 \mu \mathrm{g}$ of total RNA through a $1 \%$ agarose-formaldehyde gel followed by capillary blotting to a Zetabind membrane (CUNO, Meriden, CT). The RNA was fixed to the membrane using a Stratalinker UV-crosslinker (Stratagene, LaJolla, CA).

DNA probes were created as follows: the 786-bp rat GALT cDNA (9) was radiolabeled with $\alpha-{ }^{32} \mathrm{P}$-deoxycytidine triphosphate by random priming and a rat $18 \mathrm{~S}$ rRNA oligonucleotide (10) end-labeled with $\gamma-{ }^{32} \mathrm{P}-\mathrm{ATP}$ using T4 polynucleotide kinase. Unincorporated counts were removed by Sephadex G-50 (Sigma, St. Lous, MO) spin column chromatography.

The Northern blots were first hybridized with $6 \times 10^{6} \mathrm{cpm}$ of rat GALT cDNA in $0.5 \mathrm{M}$ sodium phosphate, $\mathrm{pH} 7.5 .7 \%$ SDS, $1 \%$ BSA, 1 mM EDTA, pH 8, $50 \mathrm{mg} / \mathrm{L}$ denatured salmon sperm DNA, and $10 \mathrm{mg} / \mathrm{L}$ polyriboadenylic acid at $68^{\circ} \mathrm{C}$ for $24 \mathrm{~h}$ followed by washing in $0.5 \times \mathrm{SSC}(75 \mathrm{mM}$ sodium chloride, 7.5 $\mathrm{mM}$ sodium citrate) $/ 0.1 \% \mathrm{SDS}$ at $68^{\circ} \mathrm{C}$ for $15 \mathrm{~min}$. Autoradiograms were generated using Kodak XAR film. The GALT 
cDNA probe was stripped from the membrane by boiling in $\mathrm{H}_{2} \mathrm{O}$. The blot was then hybridized with $1 \times 10^{6} \mathrm{cpm}$ of endlabeled rat $18 \mathrm{~S}$ rRNA probe followed by washing and autoradiography as above.

For each autoradiogram, the areas under the $18 \mathrm{~S}$ rRNA densitometry curves were brought to equivalence and the corresponding GALT densitometry curves adjusted appropriately. For comparison of different tissue survey autoradiograms, liver values from different autoradiograms were brought to equivalence and the remaining tissue values adjusted concordantly. All densitometry values obtained were determined to be in the linear range of the densitometer. The rat $18 \mathrm{~S}$ rRNA oligonucleotide probe was confirmed to be in probe excess for the quantity of 18S RNA present on the Northern blots by generation of a standardized curve (11).

GALT sp act measurement. GALT specific enzyme activity during development was measured on the same specimens as GALT mRNA with the exception of $d 1,10$, and 14; instead rat livers from $\mathrm{d} 9$ and 15 were determined and $\mathrm{d} 1$ values were as previously reported (3). Measurement of sp act in adult rat tissues was performed on the same specimens used for RNA isolation with the exception of the ovary, where published values are used (3). The measurement of GALT activity in the newborn rat liver and in the adult rat tissue specimens was based on the radioisotope method of Betoli and Segal (5). Radiolabeled $\left[{ }^{14} \mathrm{C}\right]-\mathrm{D}-$ galactose-1-phosphate was purchased from New England Nuclear (Boston, MA), all other biochemicals were products of Sigma Chemical Co. (St. Louis, MO), and ion exchange paper, diethylaminoethyl cellulose, was obtained from Whatman Inc. (Clifton, $\mathrm{NJ}$ ). Cell free homogenates were prepared by homogenizing the tissue with 8 vol $0.1 \mathrm{M} \mathrm{KCl}$ and the particulate matter removed by centrifugation at $30000 \times g$. Fifty $\mu \mathrm{L}$ of the soluble fraction were incubated with $0.25 \mathrm{mM}$ UDP glucose and 0.35 $\mathrm{mM}$ galactose- 1 -phosphate, and the linear reaction terminated at $10 \mathrm{~min}$ by immersing the tubes in boiling water. Radiolabeled substrates and the corresponding products were separated by chromatography and their respective areas counted in liquid scintillation fluid. Protein concentrations were determined using the Coumassie blue reagent and protein standard supplied by Biorad (Melville. NY). Enzyme sp act are expressed in nmol of product formed per min per $\mathrm{mg}$ of soluble protein. The data presented are the mean \pm SEM for $n=3$ to 4 animals.

\section{RESULTS}

Developmental changes in GALT $m R N A$ and $s p$ act. Figure 1 shows the autoradiogram of GALT $m$ RNA in developing rat

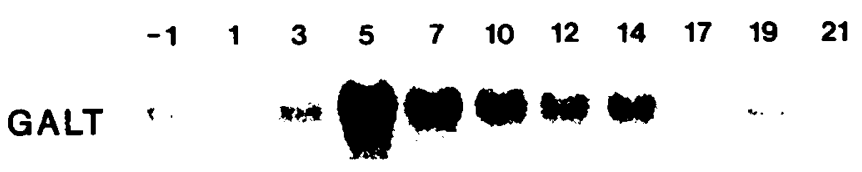

\section{$18 S$}

Fig. 1. An autoradiogram of the Northern blot analysis of steady state GALT mRNA levels in developing rat liver with respect to age. Ten $\mu \mathrm{g}$ of total RNA from pooled livers $(n=3$ or 4$)$ obtained from newborn rats on the day of life indicated were subjected to electrophoresis through a $1 \%$ agarose-formaldehyde gel and transferred to a Zetabind membrane. The Northern blot was first probed with the 782-bp rat GALT cDNA followed by a rat $18 \mathrm{~S}$ rRNA probe after removal of the GALT cDNA by boiling. Autoradiograms were generated by exposure of Kodak XAR film at $-70^{\circ} \mathrm{C}$ for $1 \mathrm{wk}$ for the GALT cDNA probe and $4 \mathrm{~h}$ for the $18 \mathrm{~S}$ rRNA probe. $18 S=$ rat $18 \mathrm{~S}$ rRNA. liver. The signal for GALT mRNA reaches maximal intensity on $\mathrm{d} 5$ in contrast to that of $18 \mathrm{~S}$ rRNA, which is not expected to vary during development. Figure 2 is a graphic representation of the densitometry values of GALT mRNA from this autoradiogram adjusted to 18S rRNA. Figure 2 also shows plots of the changes in mean GALT sp act over the same time period. Modulation of GALT specific enzyme activity mirrors that of GALT mRNA. The developmental pattern in GALT sp act found in this study is similar to that reported previously $(3,5)$.

Tissue-specific levels in GALT $m R N A$ and sp act. A representative Northern blot of tissue GALT mRNA levels is shown in Figure 3. Of note is the variation of mRNA bands detected between tissues. The lowest 1.4-kb band corresponds to the known size of GALT mRNA; also present, but differing in intensity among tissues, are $1.6-\mathrm{kb}$ and $2.0-\mathrm{kb}$ bands. The identity of these additional bands is unknown but may represent the products of either tissue-specific alternative promoters or differential splicing. Future investigations by Western blots of GALT and sequence determination of $\mathrm{mRNA}$ will determine the significance of these tissue-specific bands.

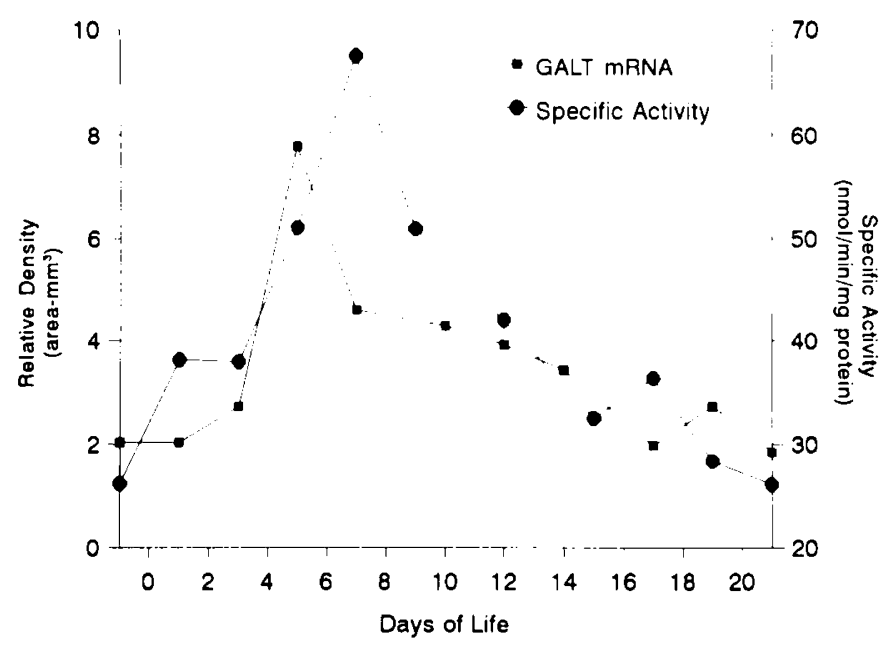

Fig. 2. Comparison of the relative abundance of GALT mRNA and levels of GALT $\mathrm{sp}$ act in the developing rat liver. GALT mRNA data represent areas obtained from densitometric analysis of the autoradiogram shown in Figure 1. GALT sp act was measured on the same samples except $d 9$ and 15 were measured instead of $d 10$ and 14 and $d$ 1 values were as previously reported (3). Data represent the mean of $n=$ 3 or 4 .

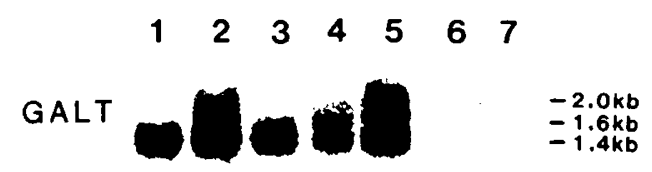

$18 S$

Fig. 3. A representative autoradiogram of a Northern blot analysis of tissue steady state GALT mRNA in the adult rat. Ten $\mu \mathrm{g}$ of total RNA from the respective adult rat tissues were subjected to electrophoresis through a $1 \%$ agarose-formaldehyde gel and transferred to a Zetabind membrane. The Northern blot was first probed with the 782-bp rat GALT cDNA followed by a rat $18 \mathrm{~S}$ rRNA probe after removal of the GALT cDNA by boiling. Autoradiograms were generated by exposure of Kodak XAR film at $-70^{\circ} \mathrm{C}$ for 1 wk for the GALT cDNA probe and $4 \mathrm{~h}$ for the $18 \mathrm{~S}$ rRNA probe. $18 \mathrm{~S}$-rat $18 \mathrm{~S}$ rRNA. Lane numbers and tissues are as follows: 1 , heart; 2 , kidney; 3 , liver; 4 , lung; 5 , ovary; 6 , skeletal muscle; 7, testis. 
Figure 4 demonstrates GALT mRNA densitometry areas for several tissues relative to liver. Liver has the highest GALT mRNA, followed by kidney, heart, ovary, lung, skeletal muscle, and testis. Figure 4 also shows GALT sp act in the same tissue. Liver has the highest sp act, followed by ovary, kidney, heart, lung, testis, and skeletal muscle.

\section{DISCUSSION}

The similarity of postnatal rat liver GALT mRNA pattern to the rise and fall of GALT sp act suggests an interrelationship of the two. The regulator of this developmental modulation may be galactose or a metabolite in the galactose metabolic pathway. The large amount of galactose, via lactose, present in rat milk may provide the stimulus for both increasing mRNA and a mechanism for enhancing the enzyme activity. Feeding highgalactose diets to adult rats has been previously shown to increase hepatic GALT sp act (2). However, the relative delay of the maximum of both mRNA and sp act, between d 5 and 7 , in contrast to the initiation of galactose intake on $d 1$, suggests that additional factors may regulate the response of these parameters.

It is interesting that the other liver enzymes of galactose metabolism exhibit developmental patterns different from GALT. Galactokinase exhibits a postnatal increase but has a sp act peak earlier than that of transferase (3). Additionally, galactokinase sp act does not increase when galactose is fed to adult rats (2) and the subsequent fall of galactokinase activity in the postnatal period cannot be prevented by early weaning to a highgalactose diet (12). UDPgalactose-4-epimerase sp act is higher in the young liver than in adult tissue but is constant during development and does not show the rise and fall seen with the other two enzymes in the pathway (13). It thus appears that the mechanism(s) for modulating GALT, galactokinase, and epimerase in the neonatal period are different. Even so, it is clear that the liver enzymes after birth are geared to a high capacity for metabolizing galactose, as has been observed in several reports using liver brei (14), isolated hepatocytes (15), and perfused liver (16).

The similarity of the pattern of tissue GALT sp act and GALT mRNA also suggests that genetic regulation is an important factor in the cellular level of the enzyme. The etiology for the tissue variation in GALT mRNA and enzyme, although unknown, may be related to differential requirements of the individual tissue for disposition of galactose. From a physiologic point of view, the liver has a high capacity of clearing galactose from blood and for its conversion to glucose (17). The highest tissue level of GALT being present in liver is consistent with this function. However, why the ovary or cardiac muscle should be endowed with high enzyme levels compared with testes and skeletal muscle is open to speculation. It is possible that tissues with higher GALT sp act have increased requirements for disposition of galactose generated from the turnover of glycoproteins and galactolipids or, alternatively, that there are tissue differences in the need for UDPgalactose for synthesis of tissuespecific glycoconjugates. Both of these possibilities relate to current theories on the pathobiochemistry of galactosemia and the poor long-term outcome with dietary therapy, namely chronic self-intoxication due to endogenous galactose-1-phosphate accumulation (18) and deficiency of UDPgalactose $(19,20)$.

In this regard, it appears that the tissues with the highest GALT mRNA and enzyme sp act are target organs for dysfunction and are affected to the greatest degree in galactosemia when GALT is genetically deficient. Liver and renal tubule dysfunction are uniformly present in acute galactose toxicity due to galactosemia (1). The fact that the ovary has approximately 5 times as much GALT mRNA and enzyme as testis parallels the observation that ovarian failure is a consistent finding in most females with galactosemia (21), whereas males with the disorder have normal testicular function (22). In a previous communication, we pointed out that rat cerebellum has the highest levels of brain GALT sp act and higher levels of GALT mRNA than cortex, which may correlate with the ataxia syndromes and cerebellar atrophy complications seen in human galactosemia (23).

For the first time, we report GALT activity in rat cardiac muscle. The high levels found are in marked contrast to the low levels in skeletal muscle. Cardiac complications have not been reported in galactosemia. However, cardiac evaluation and estimates of cardiac muscle abnormality such as creatine phosphokinase assays are not routinely performed either in the acute toxic state or on long-term follow-up. It may be that cardiac complications may not present until late in life and await recognition as the galactosemic population ages.

The exact mechanisms responsible for the developmental and tissue-specific regulation remain to be delineated. Although the mammalian pathway does not function as an operon, studies of the regulation of the GAL-operon in Saccharomyces cerevisiae offer some insights. In this organism, galactose regulates its own metabolism by increased transcription of the galactokinase
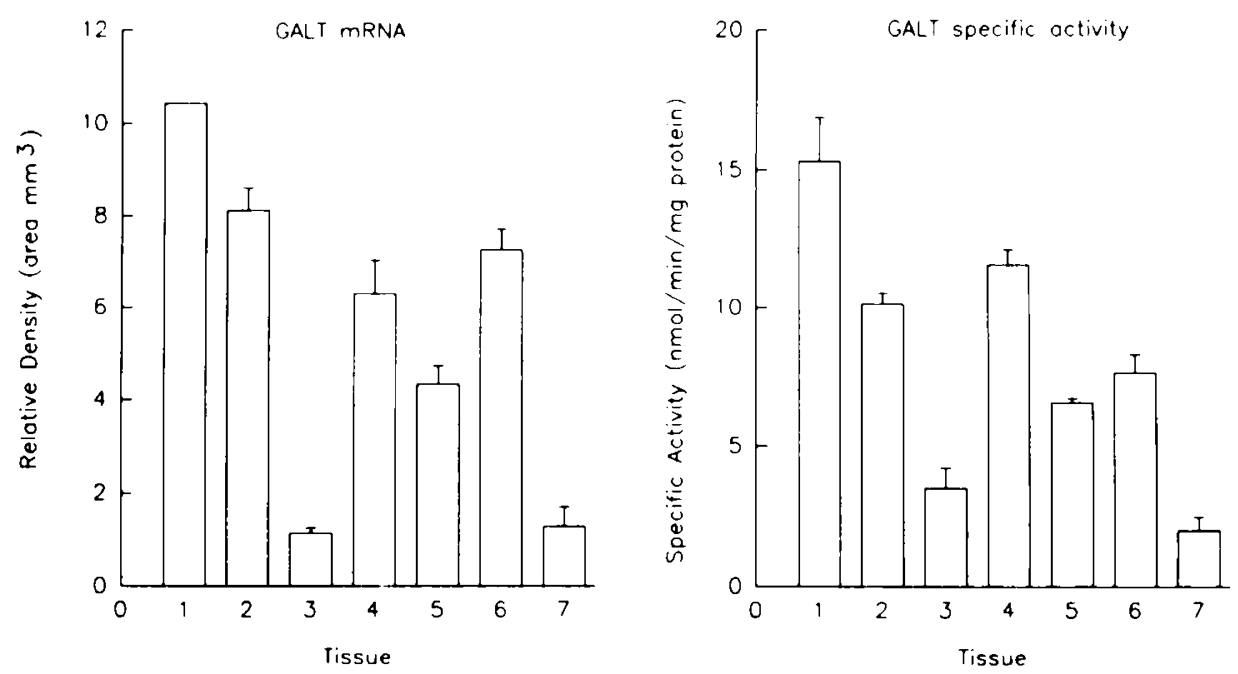

Fig. 4. Comparison of GALT mRNA and sp act between tissues in the adult rat. The left panel represents GALT steady state mRNA values. Liver densitometry values between autoradiograms were brought to equivalence and the remaining tissue values adjusted concordantly. The right panel depicts GALT sp act measured in the same tissue analyzed for mRNA except for the ovary, which represents published values (3). Data represent the mean \pm SEM for $n=3$ or 4 . Lane numbers and tissues are as follows: 1 , liver: 2, kidney; 3, testis; 4, ovary; 5 , lung; 6 , heart; 7, skeletal muscle. 
(GAL1), GALT (GAL7), and epimerase (GAL10) genes via the products of the GAL80, GAL4, and GAL3 genes (24). The operon is also under galactose catabolite repression via the products of the GAL82 and the GAL83 genes (25). It is possible that similar regulatory proteins are responsible for the response of the mammalian GALT gene to dietary galactose. Other mechanisms are likely to be responsible for tissue-specific and developmental regulation. Besides regulation of the transcription, $m R N A$ and enzyme protein degradation rates or posttranslational modification may also play an important role. Isoelectric focusing has demonstrated microheterogeneity of GALT with multiple banding patterns between adult and fetal liver (26) and adult liver and kidney (27), as well as erythrocytes and leukocytes (27) and fibroblasts (28). Reticulocytes, which have higher GALT activity than mature red cells, have additional bands on isoelectric focusing (29). Regulation of GALT sp act is likely, therefore, to be multifactorial.

We have previously reported the genomic organization of the rat GALT gene including isolation of a significant amount of 5' and $3^{\prime}$ flanking sequence (9). Availability of these flanking regions will enable detailed investigation of the rat GALT promoter and identification of tissue-specific enhancers that will hopefully illuminate our understanding of the molecular basis of the dynamic regulation of the mammalian GALT gene.

\section{REFERENCES}

1. Segal S 1989 Disorders of galactose metabolism. In: Scriver CR, Beaudet AL. Sly WS, Valle D (eds) The Metabolic Basis of Inherited Disease, 6th Ed, Vol II. McGraw-Hill. New York, pp 453-480

2. Rogers SR. Bovee BW, Saunders SL, Segal S 1989 Galactose as a regulatory factor of its own metabolism in rat liver. Metabolism 83:810-815

3. Rogers SR. Bovee BW. Saunders SL, Segal S 1989 Activity of hepatic galactosemetabolizing enzymes in the pregnant rat and fetus. Pediatr Res 25:161-166

4. Pesch L. Segal S. Topper YJ 1960 Progesterone effects on galactose metabolism in prepubertal patients with congenital galactosemia and in rats on high galactose diets. J Clin Invest 39:178-184

5. Bertoli D. Segal S 1966 Developmental aspects and some characteristics of mammalian galactose-1-phosphate uridyltransferase. J Biol Chem 241:40234029

6. Rogers S. Segal S 1991 Modulation of rat tissue galactose-1-phosphate uridyltransferase by uridine and uridine triphosphate. Pediatr Res 30:222-226

7. Rogers SR, Heidenreich RA. Mallee J. Segal S 1992 Regional activity of galactose-1-phosphate in rat brain. Pediatr Res 31:512-515

8. Chomczynski P. Sacchi N 1978 Single-step method of RNA isolation by acid guanidinium thiocyanate-phenol-chloroform extraction. Anal Biochem 162:156-159
9. Heidenreich RA Mallee J, Segal S 1993 Rat galactose-1-phosphate uridyltransferase coding sequence. transcription start site and genomic organization. DNA Sequence 3:311-318

10. Clements JA. Matheson BA. Funder JW 1990 Tissue-specific developmental expression of the kallakrein gene family in the rat. J Biol Chem 265:10771081

1. Barbu V, Dautry F 1989 Northern blot normalization with a 28 s rRNA oligonucleotide probe. Nucleic Acids Res 17:7115-7116

12. Cuatrecasas P. Segal S 1965 Mammalian galactokinase. J Biol Chem 240:2382 2388

13. Cohn R. Segal S 1969 Some characteristics and developmental aspects of rat uridine diphosphogalactose-4-epimerase. Biochim Biophys Acta 171:333341

14. Segal S, Roth H, Bertoli D 1963 Galactose metabolism by rat liver tissue: influence of age. Science 142:1311-1313

15. Rogers S, Guerra M. Segal S 1983 Galactose metabolism in suckling and adult rat hepatocytes. Pediatr Res 17:609-616

16. Berman W. Rogers S. Bautista J, Segal S 1979 Galactose metabolism in isolated perfused suckling rat liver. Am J Physiol 236:E633-E637

17. Stenstam T 1946 Peroral and intravenous galactose tests: comparative study of their significance in different conditions. Acta Med Scand 177(suppl):1115

18. Gitzelmann R, Hansen RG 1980 Galactose metabolism, hereditary defects and their clinical significance. In: Burman D. Holton JB, Pennock CA (eds) Inherited Disorders of Carbohydrate Metabolism. MTP Press Ltd, Falcon House, Lancaster, England, pp 61-101

19. Ng WG, Xu YK. Kaufman FR. Donnell GN 1989 Deficit of uridine diphosphate galactose in galactosemia. J Inherit Metab Dis 12:257-266

20. Berry GT. Palmieri MJ, Heales S. Leonard JV. Segal S 1992 Red blood cell uridine sugar nucleotide levels in patients with classic galactosemia and other metabolic disorders. Metabolism 41:783-787

21. Kaufman RF, Xu YK. Ng WG. Donnel GN 1988 Correlation of ovarian function with galactose-1-phosphate uridyltransferase levels in galactosemia. J Pediatr 122:754-756

22. Waggoner DD Buist NMR, Donnell GN 1990 Long-term prognosis in galactosemia: results of a survey of 350 cases. J Inherit Metab Dis 13:802-818

23. Lo W, Packman S, Nash S, Schmidt K. Ireland S. Diamond I, Ng WG. Donnell GN 1984 Curious neurologic sequelae in galactosemia. Pediatrics 73:309312

24. Johnston M 1987 A model fungal gene regulatory mechanism: the GAL genes of Saccharomyces cerevisiae. Microbiol Rev 51:459-476

25. Nogi Y. Fukasawa T 1983 Nucleotide sequence of the transcriptional initiation region of the yeast GAL7 gene. Nucleic Acids Res 11:8555-8568

26. Shin YS. Enders W, Rieth M Schaub J 1983 Prenatal diagnosis of galactosemia and properties of galactose-l-phosphate uridyltransferase in erythrocytes of galactosemic variants as well as in human fetal and adult organs. Clin Chem Acta 128:271-281

27. Schapira F, Gregori C, Banroques J 1978 Microheterogeneity of human galactose-1-phosphate uridyl-transferase. Isoelectricfocusing results. Biochem Biophys Res Commun 80:291-297

28. Kelley RI. Harris H. Mellman WJ 1983 Characterization of normal and abnormal variants of galactose-1-phosphate uridyltransferase (EC 2.7.7.12) by isoelectric focusing. Hum Genet 63:274-279

29. Kelley RI. Feinberg DM. Segal S 1989 Galactose-1-phosphate uridyltransferase in density fractionated erythrocytes. Hum Genet 82:99-103 